\title{
STABILITY OF SHEET WATER FLOW UNDER A GLACIER
}

\author{
By J. WEERTMAN \\ (Department of Materials Science and Engineering and Department of Geological Sciences, \\ Northwestern University, Evanston, Illinois 60201, U.S.A.) \\ and $\mathrm{G}$. E. BIRCHFIELD \\ (Department of Geological Sciences and Department of Engineering Sciences and Applied \\ Mathematics, Northwestern University, Evanston, Illinois 60201, U.S.A.)
}

\begin{abstract}
Walder recently analyzed the initial instability of water flow in a sheet under a glacier that is produced by greater heat production in the flowing water and thus the larger rate of ice melting where a perturbation has increased the water sheet thickness. We have looked at the problem from the other presumed final state. We assume that instabilities have finally caused all the water to flow in channels (R-channels) at the bed. We investigated whether these channels can collect enough of the water that is produced by the geothermal heat and the heat sliding to remain in existence. When a basal shear stress is present, the distance out to which a channel can collect water is not that much greater than the channel radius itself. It is concluded that it is not likely for the channel to be able to collect appreciable amounts of water that is produced at the bed. Hence despite the indication that an instability initially might grow in a water sheet, this instability either cannot develop to the point when the water flow is primarily in channels or else the water flow alternates cyclically between a state primarily of sheet flow and a state of channel flow. It would appear that the channels that do exist under a glacier have their primary origin in the melt water from the upper surface that pours down moulins and thus is already channelized by the time it reaches the bed.
\end{abstract}

RÉSumÉ. Stabilité de l'écoulement d'eau en nappe sous un glacier. Walder a récemment analysé l'instabilité initiale de l'écoulement d'eau en nappe sous un glacier en raison de la plus grande production de chaleur dans l'eau courante et donc de la plus forte fusion lorsqu'une perturbation a accru l'épaisseur du film liquide. Nous avons examiné le problème à partir de l'ètat final présumé. Nous supposons que les instabilités ont finalement provoqué la concentration de tous les écoulements liquides dans des chenaux (chenaux-R) dans le lit. Nous avons cherché à voir si ces chenaux peuvent recueillir suffisamment de l'eau produite par le flux géothermique et la chaleur de glissement pour rester actifs. Lorsqu'il y a un effort de cisaillement au fond, la distance sur laquelle un chenal peut recueillir de l'eau n'est pas beaucoup plus grande que le rayon du chenal lui-même. On conclut qu'il n'est pas probable qu'un chenal recueille une part appréciable de l'eau produite au contact du lit. Par conséquent, malgrè les raisons d'une instabilité initiale de la nappe d'eau liquide cette instabilité ou bien ne peut pas se développer lorsque l'eau est principalement dans des chenaux ou bien les eaux présentent des stades alternatifs cycliques d'écoulement en nappe et d'écoulement en chenaux. Il semblerait que les chenaux qui existent en réalité sous un glacier ont leur première origine dans les eaux de fontes de surfaces qui sont dejjà concentrées dans des moulins au cours de leur descente vers le fond.

Zusammenfassung. Stabilität des Schichtwasserflusses unter einem Gletscher. Walder analysierte jüngst die anfängliche Instabilität des Wasserflusses in einer Schicht unter einem Gletscher, die durch die höhere Wärmeproduktion im fliessenden Wasser und die damit verbundene grössere Schmelzrate an Stellen, wo eine Störung die Dicke der Wasserschicht verstärkt, hervorgerufen wird. Wir haben das Problem von der anderen Seite her, nämlich dem angenommenen Endzustand, angegangen. Wir nehmen an, dass infolge von Instabilitäten schliesslich alles Wasser in Kanälen am Untergrund (R-Kanälen) fliesst. Wir untersuchten, ob diese Kanäle genug von dem durch geothermische Wärme erzeugten Wasser aufnehmen können und ob das Gleiten infolge Erwärmung aufrecht erhalten bleibt. Wenn eine Scherspannung am Untergrund vorhanden ist, ist die Entfernung. bis zu der ein Kanal Wasser sammeln kann, nicht viel grösser als der Radius des Kanals selbst. Daraus lässt sich schliessen, dass der Kanal vermutlich keine nennenswerten Wassermengen, die am Untergrund erzeugt werden, aufnehmen kann. Obwohl also eine Instabilität in einer Wasserschicht zunächst zunehmen mag, kann sich diese Instabilität entweder nicht bis zu jenem Grad entwickeln, bei dem das Wasser hauptsächlich in Kanälen fliesst, oder der Wasserfluss wechselt zyklisch zwischen einem Zustand des Schichtflusses und einem solchen des Flusses 
in Kanälen. Es scheint wahrscheinlich, dass die Kanäle, die unter einem Gletscher tatsächlich vorhanden sind, in erster Linie von dem Oberflächenschmelzwasser gebildet werden, das bereits in Mühlen gefasst ist, wenn es zum Untergrund abfliesst.

\section{INTRODUCTION}

Walder (1982), in a beautifully developed analysis, has investigated the initial stability of water flow in a sheet at the base of a glacier against developing a melting instability that favors diversion of water flow into channels. He showed that if some section of the water sheet were to become slightly thicker, more water would flow through it under the same pressure gradient. In turn more heat would be generated in the flowing water which would melt ice at a greater rate from the ice roof. The greater melting rate would cause the section to become even thicker. Increased downward ice flow by creep deformation presumably would eventually halt this process and finally leave an ice channel of radius considerably larger than the original thickness of the water film. This possible instability of the flow of water in a sheet at the base of a glacier was pointed out, but not analyzed, by Nye (1976). The physical processes involved had earlier formed the basis of the theory of Röthlisberger channels (R-channels) at the base and within glaciers (Röthlisberger, 1972, 1973; Shreve, 1972; Weertman, 1972). R-channels are water channels at the base of a glacier that are incised upwards into the ice itself rather than downwards into the bed. The latter are Nye channels ( $\mathrm{N}$-channels).

It has been pointed out (Weertman, 1972) that it may be very difficult for R-channels to be supplied with sufficient water to keep them open if the water supply for the channels is developed at the base of the glacier (from geothermal heat and the heat of sliding) rather than from upper surface melt water that descends to the base in moulins. The difficulty is that the pressure field around an R-channel can be such as to drive water away from the tunnel rather than towards it, even though the water pressure within the channel is lower than the average ice overburden pressure. This difficulty was pointed out by Walder in his paper but no attempt was made to assess its importance. The purpose of this paper is to make this assessment.

It should be pointed out that the water film that is being considered in this paper presumably exists in the zones between the contact regions of very high pressure on the up-stream sides of bed bumps or bed undulations and any large cavities that may exist on the down-stream sides of bumps and undulations. We emphasize that measurements of uplift and sinking of the upper surface of a glacier, such as have been reported recently by Iken and others (1982), do not necessarily reflect changes in the average thickness of the water film. A discussion is given in the Appendix on how to define an average thickness for the water film.

\section{THEORY}

Consider first the case in which all the water flowing at the bed originates there by the melting produced by the geothermal heat and the heat of sliding. Let $\lambda_{b}$ be the average thickness of ice (converted into water thickness) melted from the bottom per unit time. If this water were to flow as a sheet, the amount of water $Q$ per unit transverse distance at a distance $L$ from the head of a glacier of constant width is equal to

$$
Q=\lambda_{\mathrm{b}} L
$$

We now show that the additional melting due to viscous dissipation in the water film is negligible. 
If $P^{\prime}$ is the pressure gradient driving the water flow, the amount of work $W$ done per unit area and time at point $L$ is equal to

$$
W=Q P^{\prime}=\lambda_{\mathrm{b}} L P^{\prime} .
$$

The average pressure gradient $P^{\prime}$ to a first-order approximation is equal to $\rho g \alpha$ where $\rho$ is the density of ice, $g$ is the gravitational acceleration, and $\alpha$ is the slope of the upper ice surface. Since the basal shear stress $\tau$ to a first-order approximation is equal to $\rho g h \alpha$ where $h$ is the ice thickness, $P^{\prime} \simeq \tau / h$. The work $W$ can melt in unit time an ice layer of thickness $\lambda$ equal to

$$
\lambda=\lambda_{\mathrm{b}} L P^{\prime} / H
$$

where $H$ is the heat of fusion of ice. (A more accurate expression for $\lambda$ (private communication from J. S. Walder) that takes into account the fact that $Q$ increases with distance down a glacier is $\lambda=\left(\lambda_{\mathrm{b}} P^{\prime} / H\right)(L-h)$. We assume that $L \gg h$ and use the approximate expression given by Equation (3).) Since $H=306 \mathrm{MJ} / \mathrm{m}^{3}$ and a typical value of $P^{\prime}$ is of the order of $200 \mathrm{~Pa} / \mathrm{m}$ (for $\tau=100 \mathrm{kPa}$ and $h=500 \mathrm{~m}$ ) the thickness $\lambda$ that is melted per unit time is a factor $0.0060 \mathrm{smaller}$ than the rate of melting $\lambda_{\mathrm{b}}$ for $L=10 \mathrm{~km}$ and a factor 0.06 smaller for $L=100 \mathrm{~km}$. Thus $\lambda$ is trivial in magnitude compared with $\lambda_{\mathrm{b}}$. There is no need to correct the value of $\lambda_{\mathrm{b}}$ for the additional melting produced by viscous energy dissipation in the moving water. Although the amount of viscous heating is small compared with the geothermal heat and the heat of sliding we emphasize strongly that this heat, nevertheless, is the origin of the instability of the water film.

Suppose R-channels develop because of the water-film instability that was studied by Walder. Figure 1 shows a transverse cross-section of a glacier bed with R-channels of diameter $d$ that are spaced a distance $D$ apart. Consider that virtually all the water flow is through these channels. The velocity $\lambda^{\star}$ at which ice is melted from the tunnels walls by the energy dissipated in water flow is equal to

$$
\lambda^{\star}=\lambda(D / d)=\lambda_{\mathrm{b}}\left(L P^{\prime} / H\right)(D / d)
$$

because the work term $W$ of Equation (2) is the same regardless of the water flow pattern. (The pressure gradient in a tunnel, in general, differs from the expression $\rho g \alpha$ because of the need of the pressure difference $\Delta P$ given in Equation (5) below to take on particular values in a steadystate situation (Röthlisberger, 1972, 1973). However, if the tunnel is very long compared with the thickness of a glacier, $P^{\prime}$ is approximately equal to or is of the same magnitude as the expression $\rho g \alpha$. For the purposes of the analysis of this paper no significant error is introduced by assuming that $P^{\prime}=\rho g \alpha$ in Equation (4) and by ignoring the correction mentioned earlier that takes into account that $Q$ is not a constant.)

Because no ice is melted from the heat evolved in water flow in the regions between the tunnels, the water pressure drop $\Delta P$ between the ice and the interior of the tunnel must be just large enough for the closure of the tunnel by creep deformation to match the velocity of melting $\lambda^{\star}$ when the tunnel diameter remains constant. The velocity $v$ at which the tunnel walls close in is equal to

$$
v=C d(\Delta P)^{n}
$$

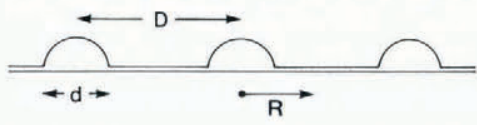

Fig. 1. Transverse cross-section of glacier bed with $R$-channels that are parallel to direction of glacier flow. 
where $C$ is a constant. This is the usual Nye tunnel-closing expression. The power exponent $n$ will hereafter be taken as $n=3$ and the constant $C=1.7 \times 10^{-23} \mathrm{~Pa}^{-n} \mathrm{~s}^{-1}$. These are the values of the constants used in Weertman (1972). Equating Equations (4) and (5) gives

$$
D=C d^{2}\left(H / \lambda_{\mathrm{b}} L P^{\prime}\right)(\Delta P)^{n} .
$$

If the shear stress $\tau$ at the base of a glacier is large compared with $\Delta P$, Equation (5) is replaced with (Weertman, 1972, equation (31))

$$
v=C^{\prime} d \tau^{n-1} \Delta P
$$

where $C^{\prime}=n^{n} C$. A large shear stress effectively linearizes the closure problem with respect to the pressure drop $\Delta P$. More important than the effect on closure velocity, however, is the qualitative change that is produced in the pressure field around a tunnel at the ice-rock contact surface (Weertman, 1972).

If $\tau$ is negligibly small compared with $\Delta P$, Equation (5) is valid and the pressure gradient at the ice-rock contact is given by (Weertman, 1972, equation (28))

$$
P_{\mathrm{g}}=-\Delta P\left[2(n-2) / n^{2}\right](d / 2 r)^{(2+n) / n}
$$

where $P_{\mathrm{g}}$ is the gradient in the direction normal to the $\mathrm{R}$-channel axis and $r$ is the distance from the center of the channel $(r>d)$. The sign of $P_{\mathrm{g}}$ in Equation (8) when $n>2$ is such that water is driven towards the channel. If $\tau$ is large compared with $\Delta P$ Equation (7) is valid and $P_{\mathrm{g}}$ is given by

$$
P_{\mathrm{g}}=\Delta P(d / 2 r)^{3} .
$$

The pressure gradient now drives water produced at the rock-ice interface away from the channel. If $\tau$ is small compared with $\Delta P$ but is not negligible there is a critical distance $R$ from the tunnel center out to which any water produced at the ice-rock interface is driven toward the tunnel and any water produced at a larger distance than $R$ is driven away from the tunnel. The distance $2 R$ is given by (Weertman, 1972, equation (33))

$$
2 R=d(\Delta P / \tau)^{n / 2} .
$$

Therefore, an R-tunnel can only collect water out to the distance $R$ given by Equation (10).

If the distance $2 R$ at a given pressure drop $\Delta P$ given by Equation (10) is equal to or larger than the distance $D$ given by Equation (6), clearly an R-channel has no difficulty in collecting all the water produced by the geothermal heat and the heat of sliding. However, if $2 R<D$ the tunnel cannot collect all of the water. Consequently there is a maximum separation $D$ of the $\mathrm{R}$-channels beyond which it is not possible for them to exist in a steady-state condition. The value of $d$ in Equations (6) and (10) was found by noting that the amount of water flowing in a channel is equal to

$$
Q=\lambda_{\mathrm{b}} D L \text {. }
$$

The tunnel diameter is related to $Q$ for laminar water flow by the well known equation

$$
Q=\pi d^{4} P^{\prime} / 128 \mu
$$

where $\mu$ is the viscosity of water ( $\mu=1.8 \mathrm{mPa} \mathrm{s}$ ). Combining Equations (6), (11), and (12) gives

$$
D=\left(128 \mu C^{2} H^{2} / \pi \lambda_{\mathrm{b}} L P^{\prime 3}\right)(\Delta P)^{2 n} .
$$


Combining Equations (10), (11), and (12) gives

$$
2 R=\left(128 \mu \lambda_{\mathrm{b}} D L / \pi P^{\prime}\right)^{1 / 4}(\Delta P / \tau)^{n / 2}
$$

where $D$ is given by Equation (13). The value of $D$ is found by combining Equations (6) and (10) and is equal to

$$
D=\lambda_{\mathrm{b}} L P^{\prime} / C H \tau^{n} .
$$

The value of $D$ is independent of the values of $d$ and $\Delta P$. For $\lambda_{\mathrm{b}}=1 \mathrm{~cm} /$ year, $L=50 \mathrm{~km}$, $P^{\prime}=200 \mathrm{~Pa} / \mathrm{m}, C=1.7 \times 10^{-23} \mathrm{~Pa}^{-n} \mathrm{~s}^{-1}, n=3, H=306 \mathrm{MJ} / \mathrm{m}^{3}$, and $\tau=100 \mathrm{kPa}$, the value of $D$ is $0.6 \mathrm{~mm}$. This value of R-tunnel separation is so extremely small that it is very good proof that sheet water flow is stable against a final collapse into steady-state water flow by R-channels.

A graphical display of the results of Equations (6), (10), (13), and (14) will, perhaps, make the conclusions reached from them clearer. In Figure 2 a plot of the terms $D$ and $2 R$ versus pressure difference $\Delta P$ is given. To the left of the intersection of the curves of $D$ versus $\Delta P$ and $2 R$ versus $\Delta P, D$ is smaller than $2 R$. Thus for values of $\Delta P$ to the left of the intersection the tunnel spacing is sufficiently small that the R-channels are capable of absorbing all the water that is produced at the bed. To the right of the intersection $D$ is larger than $2 R$. The channel spacing is not small enough to insure that all the water produced at the bed can be captured by the channels. In Figure 2 it is seen that at the intersection of $2 R$ and the $D$ lines for $\lambda_{\mathrm{b}}=1 \mathrm{~cm} /$ year, the pressure drop $\Delta P$ is actually smaller than $\tau$, a result that implies that no water at all is entering the R-tunnels and the value of $D$ obtained from the equations is actually too large! Even under surge conditions when $\lambda_{\mathrm{b}}$ is likely to be increased to values of the order of 1 to $2 \mathrm{~m} / \mathrm{year}$ the value of $D$ is only increased to about 5 to $10 \mathrm{~cm}$.

In Figure 3 the terms $D$ and $2 R$ are plotted as a function of $d$. It is seen that for the case of $\Delta P=100 \mathrm{kPa}$ when $D=2 R$ that $d=0.56 \mathrm{~mm}$ and that $D$ and $2 R$ are also equal to $0.56 \mathrm{~mm}$. For $\Delta P=1 \mathrm{MPa}$ the intersection occurs at $d=0.018 \mathrm{~mm}$ with $d$ and $2 R$ again equal to $0.56 \mathrm{~mm}$. In the region to the right of the intersections in Figures 2 and 3 channels cannot tap enough water to stay open. Channels in this left-hand region will grow in size, reduce their number, and increase their spacing until the spacing is that of the intersection point. Only at the intersection

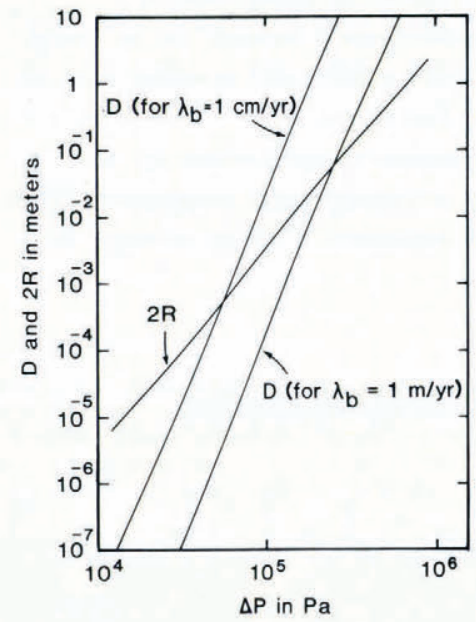

Fig. 2. Double logarithmic plot of tunnel separation distance $D$ or twice water-collection distance $R$ versus pressure drop $\triangle P$ in $R$-channels. The following values of the terms were used to obtain the plots: $\lambda_{b}=1 \mathrm{~cm} /$ year and $1 \mathrm{~m} /$ year $\quad L=50 \mathrm{~km}, \quad P^{\prime}=200 \mathrm{~Pa} / \mathrm{m}$, $\mu=1.8 \mathrm{mPas}$, and $\tau=100 \mathrm{kPa}$. The tunnel diameter was found using Equation (12) with $Q=\lambda_{b} L D$. 


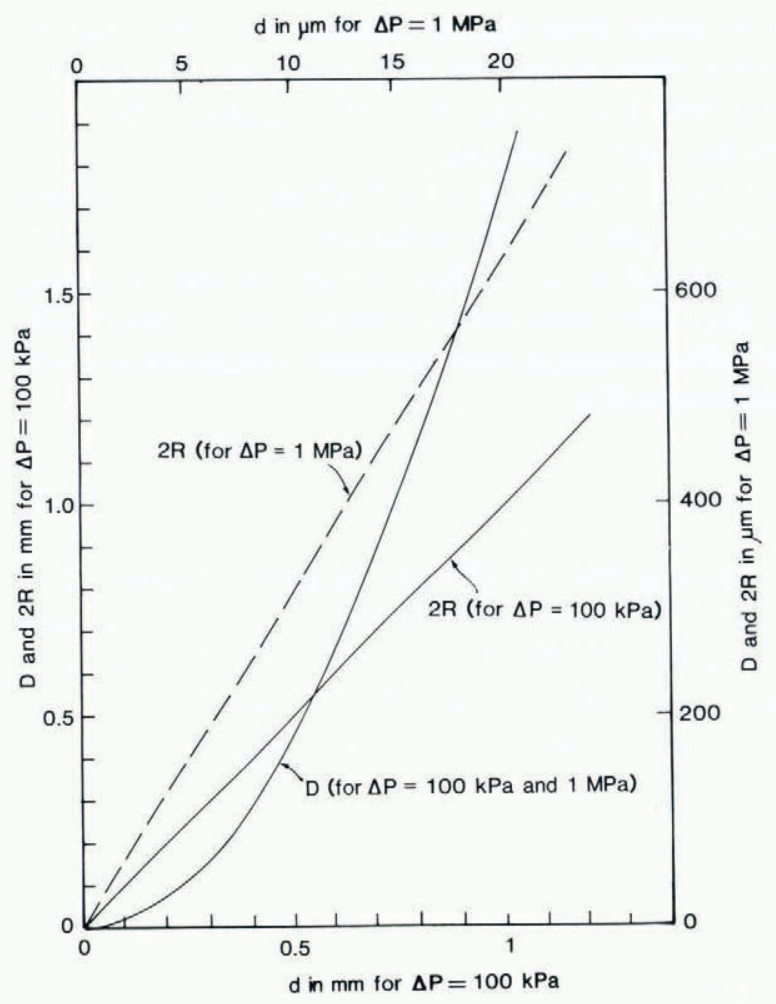

Fig. 3. Plot of $D$ or $2 R$ versus $d$ calculated with $\tau=100 \mathrm{kPa}, L=50 \mathrm{~km}, P^{\prime}=200 \mathrm{~Pa} / \mathrm{m}$, and $\lambda_{b}=1 \mathrm{~cm} /$ year.

can a steady-state situation exist. However, it is seen in Figures 2 and 3 that the channel spacing is so small as to make meaningless the concept of channelized water flow.

Consider another example that demonstrates why the R-tunnels cannot collect enough water to maintain themselves. Suppose there were an R-channel that could collect all the water produced on either side of it out to a distance of $R=5 \mathrm{~m}$. From Equations (11) and (12) the channel diameter $D=1.6 \mathrm{~cm}$ with $\lambda_{\mathrm{b}}=1 \mathrm{~cm} /$ year, $L=50 \mathrm{~km}$, and $P^{\prime}=200 \mathrm{~Pa} / \mathrm{m}$. But if this value for $d$ is placed in Equations (6) and (10), it is found that $R=7.7 \mathrm{~cm}$, so a discrepancy of two orders of magnitude exists between the two values of $R$.

\section{Discussion}

There is no question that the instability analysed by Walder should develop in the flow of a water sheet under a glacier. There is also no question that were it to develop to the point that all the water is flowing in R-channels then these must disappear because they cannot be nourished with sufficient water. Consequently the sheet flow would reappear. What then does happen? An idealized sheet of constant thickness might develop small undulations with a wavelength much greater than the average sheet thickness. Unlike the situation we have analyzed, water could then flow from the thinner regions into the thicker regions. The sheet flow still remains essentially a sheet situation. Another situation that can be imagined is not the quasi-static steady state one but a cyclic case. A sheet flow collapses quickly into tunnel flow with the amount of water in the 
tunnels being that present during the time of collapse. When this water drains out of the channels the channels themselves collapse and the water sheet is reestablished. This cyclic change need not take place simultaneously over the whole bed. Local areas that are in random phase with other local areas might cyclically switch from one form to the other.

However, whether water flow occurs in a cyclic mode or in a modified sheet flow it is likely that sheet flow must remain important in ridding a glacier of the water that has its origin at the base of a glacier. Melt water that originates at the upper ice surface of a glacier can, of course, remain channelized when it descends to the bed. Only during times of excess upper-surface meltwater production, during short time periods before channels have enlarged sufficiently to carry this more abundant supply, would such water enter a film.

\section{ACKNOWLEDGEMENTS}

This research was sponsored in part by funding from the Climate Dynamics Section of the National Science Foundation under Grants ATM-78/3961 and ATM-81/1138. The figures were drafted by Cheril Cheverton. We wish to thank Mr J. S. Walder for his very helpful comments on improving the draft version of our paper. We thank $\mathrm{Dr} \mathrm{H}$. Röthlisberger and Dr A. Iken for an interesting correspondence and discussion about the average value of the water film thickness.

$M S$. received 13 April 1983

\section{APPEndix. Best SPATial AVERAge VAlue of water film thickness?}

The water film thickness at the bed of a glacier is not a constant. It varies spatially (in addition to any temporal variations). On the down-stream side of bed bumps, water-film cavities can exist whose vertical dimension can be quite large. (Observations on the Unteraargletscher (Iken and others, 1983) reveal that parts of this glacier undergo uplift up to $0.6 \mathrm{~m}$ at the beginning of the melt season. Presumably such uplift is produced by an enlargement of the volume of water in cavities.) On the up-stream side of bumps in the bed, the water film thickness is almost zero. Here the bed pressure is greatest. Water never flows into these high-pressure regions. Regelation-produced water is squeezed out of them.

Neither of the two usual types of physical average of non-uniform properties describes well the water film thickness. The Voigt average $w_{\mathrm{v}}$ of the water film thickness $w(x, y)$ is defined by

$$
w_{\mathrm{v}}=A^{-1} \int w(x, y) \mathrm{d} x \mathrm{~d} y
$$

where $A$ is bed area and $x$ and $y$ are spatial coordinates that are parallel to the mean bed surface. The Reuss average $w_{\mathrm{r}}$ is defined by

$$
w_{\mathrm{r}}^{-1}=A^{-1} \int w^{-1} \mathrm{~d} x \mathrm{~d} y .
$$

The Voigt average overemphasizes the areas with water cavities. (The uplift data just mentioned are a Voigt average of bed separation changes.) The Reuss average overemphasizes the highpressure regions on the up-stream side of bumps. 
We suggest that the equation

$$
w_{\mathrm{a}}^{-1}=\beta A^{-1} \int\left[2 w /\left(w^{2}+w_{\mathrm{a}}^{2}\right)\right] \mathrm{d} x \mathrm{~d} y
$$

is a reasonable one to use to define the average value $w_{\mathrm{a}}$ of the water film thickness. In Equation (A-3) $\beta$ is the smallest constant that can be chosen and still have a solution of the equation. (For a film of constant thickness $\beta=1$.) Neither minor areas of unusually large or unusually small water-layer thickness can dominate the average defined by Equation (A-3). For example, suppose $w=1 \mathrm{~mm}$ over $90 \%$ of the bed area, $w=10 \mathrm{~m}$ over $5 \%$ of the area, and $w=1 \mathrm{~nm}$ over the remaining $5 \%$ area. Obviously, a reasonable average value of the water film thickness should be close to $1 \mathrm{~mm}$ since this is the value of the water film thickness over most of the area of the bed. But the Voigt average is $w_{\mathrm{v}}=0.501 \mathrm{~m}$ and the Reuss average is $w_{\mathrm{r}}=1.99 \mu \mathrm{m}$ in this example. Neither of these averages is close to $1 \mathrm{~mm}$. However, the average given by Equation $(\mathrm{A}-3)$ is $w_{\mathrm{a}}=0.999995 \mathrm{~mm}$ with $\beta=10 / 9$. Hence Equation $(\mathrm{A}-3)$ gives a reasonable value of $w_{\mathrm{a}}$ if $\beta$ is chosen to have the smallest value possible. It is clear that uplift data, such as those obtained by Iken and others (1983) for Unteraargletscher, are not necessarily a good measure of the change in the water-layer thickness at the bed of a glacier although they are a good measure of changes in the Voigt average.

To obtain a minimum $\beta$, equation (A-3) is differentiated with respect to $w_{\mathrm{a}}$ and $\mathrm{d} \beta / \mathrm{d} w_{\mathrm{a}}$ is set equal to zero yielding the following equation for $w_{\mathrm{a}}$

$$
\int\left[w /\left(w^{2}+w_{\mathrm{a}}^{2}\right)\right] \mathrm{d} x \mathrm{~d} y=2 w_{\mathrm{a}}^{2} \int\left[w /\left(w^{2}+w_{\mathrm{a}}^{2}\right)^{2}\right] \mathrm{d} x \mathrm{~d} y .
$$

Equation (A-4) may have multiple solutions because there may be more than one value of $\beta$ for which $\mathrm{d} \beta / \mathrm{d} w_{\mathrm{a}}=0$. For example, Equation $(\mathrm{A}-4)$ gives $w_{\mathrm{a}}=w_{0}$ and $w_{\mathrm{a}}=0$ for the case when the water-layer thickness is essentially equal to 0 over a fraction $f$ of the bed is equal to $w_{0}$ over the remaining fraction $(1-f)$. The value of $\beta=1 / f$ for $w_{\mathrm{a}}-w_{0}$ and $\beta=1 /(1-f)$ for $w_{\mathrm{a}}=0$. Thus by our definition of $w_{\mathrm{a}}$ if $f \ll 1, w_{\mathrm{a}}=w_{0}$ and $\beta \simeq 1$; if $(1-f) \ll 1, w_{\mathrm{a}}=0$ and $\beta \simeq 1$, as expected.

We emphasize that there are cases when a single value for $w_{\mathrm{a}}$ for the average thickness of the water film thickness by any definition does not make good physical sense. In the example just considered if $f$ is neither close to 1 nor to 0 in value and thus is of order of magnitude of 0.5 no single value of $w_{\mathrm{a}}$ describes well the water-layer thickness. The Reuss average gives $w_{\mathrm{r}}=0$; the Voigt average gives $w_{\mathrm{v}}=f w_{0}$. Neither of these values gives a reasonable account of the thickness of the water film at the bed. A value of $w_{\mathrm{r}}=0$ disguises the fact that $w=w_{0}$ over a major fraction of the bed. A value of $w_{\mathrm{v}}=f w_{0}$ conceals the fact that $w=0$ over a major fraction of the bed and gives a water thickness which is about $50 \%$ in error over the fraction of the bed where the water film thickness is finite. Our definition, depending on whether $f>0.5$ or $f<0.5$ gives either $w_{\mathrm{a}}=$ $w_{0}$ or $w_{\mathrm{a}}=0$. These results are just as unsatisfactory. However, when Equation $(\mathrm{A}-4)$ does give multiple solutions for $w_{\mathrm{a}}$ the value of $1 / \beta$ that corresponds to each value of $w_{\mathrm{a}}$ is a measure of the fraction of the bed for which the water-film thickness is of the order of the solution $w_{\mathrm{a}}$. Thus one need only specify that when Equations $(\mathrm{A}-3)$ and $(\mathrm{A}-4)$ produce multiple solutions for $w_{\mathrm{a}}$ and the smallest value (and possibly the next-but-one smallest value) that a single value of $w_{\mathrm{a}}$ is invalid (if $w_{\mathrm{a}}$ corresponding to these two smallest (or three smallest) values of $\beta$ are not themselves approximately equal to each other). The best estimate to use for the water-film 
thickness in this situation is the largest value of $w_{\mathrm{a}}$ given by the smallest two or three values of $\beta$. Over a major fraction of the bed, the water-film thickness will approximate to this solution.

\section{REFERENCES}

Iken, A., and others. 1983. The uplift of Unteraargletscher at the beginning of the melt season-a consequence of water storage at the bed? By A. Iken, H. Röthlisberger, A. Flotron, and W. Haeberli. Journal of Glaciology, Vol. 29, No. 101, p. 28-47.

Nye, J. F. 1976. Water flow in glaciers: jökulhlaups, tunnels, and veins. Journal of Glaciology, Vol. 17, No. 76, p. 181-207.

Röthlisberger, H. 1972. Water pressure in intra- and subglacial channels. Journal of Glaciology, Vol. 11, No. 62, p. $177-203$.

Röthlisberger, H. 1973. Water pressure in subglacial channels. Union Géodésique et Géophysique Internationale. Association Internationale d'Hydrologie Scientifique. Commission de Neiges et Glaces. Symposium on the Hydrology of Glaciers, Cambridge, 7-13 September 1969, p. 97. (Publication No. 95 de l'Association Internationale d'Hydrologie Scientifique.) [Abstract.]

Shreve, R. L. 1972. Movement of water in glaciers. Journal of Glaciology, Vol. 11, No. 62, p. 205-14.

Walder, J. S. 1982. Stability of sheet flow of water beneath temperate glaciers and implications for glacier surging. Journal of Glaciology, Vol. 28, No. 99, p. 273-93.

Weertman, J.1972. General theory of water flow at the base of a glacier or ice sheet. Reviews of Geophysics and Space Physics, Vol. 10, No. 1, p. 287-333. 